\title{
Comprehensive review on the biological width, functional and esthetic requirements of crown lengthening procedure illustrated with a clinical case
}

\author{
Senny Thomas Parackal ${ }^{1, *}$, Jose Paul ${ }^{2}$, Johnson Prakash ${ }^{3}$, Binitta Paul K ${ }^{4}$, Paulson George ${ }^{5}$ \\ ${ }^{1,3}$ Professor, ${ }^{2}$ Professor and HOD, ${ }^{4}$ Seinor Lecturer, ${ }^{5}$ Post Graduate Student, Dept. of Periodontics, Annoor Dental College \& \\ Hospital, Muvattupuzha, Kerala, India \\ *Corresponding Author: \\ Email: drsenny31@gmail.com
}

\begin{abstract}
There is a close symbiotic relationship between periodontal health and teeth restorations as a healthy periodontium that is in harmony with the restorative margins is vital for a successful restoration. The prevention of violation of the biological width is an inevitable aspect for the success of fixed partial dentures and crowns. This case report involves crown lengthening procedure that allows preservation of the biologic width and successful placement of the prosthesis with a good prognosis. This article also emphasizes on the importance of an appropriate treatment plan with interdisciplinary approach by discussing the various aspects of crown lengthening.
\end{abstract}

Keyword: Bilogic width, Attached gingiva, Clinical crown, Crown lengthening, Functional, Esthetic.

\section{Introduction}

A short clinical crown can cause poor retention form due to improper tooth preparation. In order to overcome the poor outcomes due to short clinical crown length, surgical crown lengthening can be done. This can be done without affecting the biologic width. Fixed prosthodontic treatment is a fundamental part in dentistry today. However positive outcomes of treatment in the form of maintenance and durability of dental prosthesis depend on healthy periodontium. Apart from this, a healthy appearance of the tooth and tissue interface along with the surrounding gingiva is as important as the periodontium, as this contributes to the patient's esthetic appearance.

Biological width is the physiologic dimension of the junctional epithelium and the connective tissue attachment. Biological width intrusion by placement of a restoration in its zone may result in gingival inflammation, pocket formation, abscess formation and alveolar bone loss. Fixed partial denture (FPD) success depends on efficient preservation of the biological width. Crown lengthening, a periodontal intervention plays an important role in preserving the fore mentioned biological width, thereby affecting the long term prognosis of the FPD.

\section{Case Report}

A 23 year old female patient with a chief complaint of missing back teeth, was referred from the department of prosthodontics with very small clinical crown and decreased space to accommodate the pontic of FPD (Fig. 1). On examination, crown structure on 34, 35, 38 were inadequate for prosthetic crown preparation and inter occlusal distance was less (Fig. 2). There was deep caries which involved the pulp on 38 .

Based on our above clinical findings, a treatment plan was charted out. It included an endodontic treatment in 38 and flap surgery with osteoplasty/osteotomy. Patient was prepared for the periodontal surgery after conducting routine blood investigations.

The surgical procedure was as follows:

1. Internal bevel incision in relation to the teeth was made as two parallel incisions on the crest.

2. A thin strip of gingiva between the parallel incisions and the secondary flap were removed. The primary flap was elevated.

3. Osseous reduction of the crest of the alveolus was done to increase the clearance between occlusal plane and alveolar ridge in the edentulous area.

4. Ostectomy was done in relation to 34,35 and 38 to increase the clinical crown height with a provision of sufficient area for biologic width attachment (Fig. 3).

5. Flaps were closed at a lower level with respect to the cemento-enamel junction of the adjacent tooth (Fig. 4).

Patient was called after 1 week of surgery for suture removal and later reviewed at 2 weeks interval. The healing was satisfactory and the supra structure was sufficient for a restoration with the prosthesis (Fig. 5).

There was also sufficient inter occlusal space for a pontic (Fig. 5). FPD was fabricated and delivered after 6 months.

A healthy collar of gingiva was established without affecting the biologic width and attached gingival zone (Fig. 6).

For proper periodontal maintenance, patient was advised for a periodic review once in every six months. Patient was followed up for three years. There was no pockets or inflammation around the prosthesis (Fig. 7). 


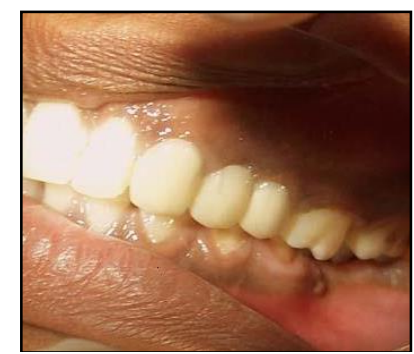

Fig. 1: Short clinical crown irt 34,35,38

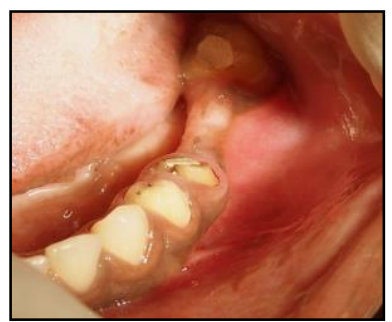

Fig. 2: Occlusal view, insufficient clinical crown height

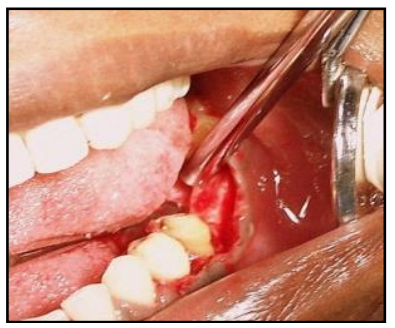

Fig. 3: Osseous reduction of the crest of the alveolus and Ostectomy done irt 34,35,38

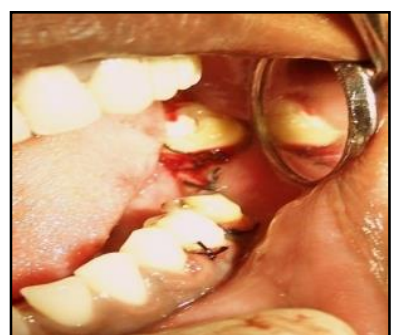

Fig. 4: Flaps closed at a more apical level with respect to $\mathrm{CEJ}$

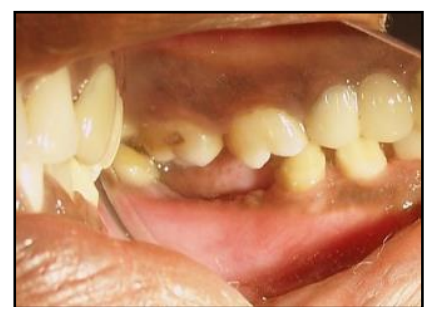

Fig. 5: 2 weeks post operative view indicates sufficient crown structure and inter occlusal space for pontic

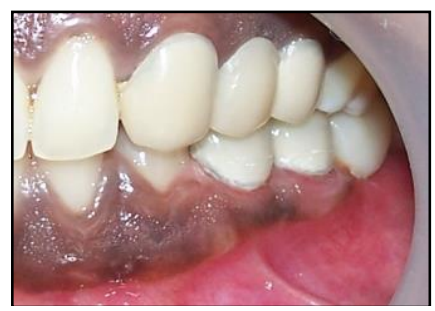

Fig. 6: Fixed partial denture was fabricated and delivered after 6 months. A healthy collar of gingiva was established without breaching the biologic width and attached gingival zone

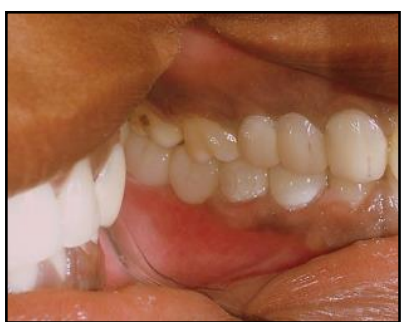

Fig. 7: Three year follow-up results appeared to be satisfactory without any pockets or inflammation around the prosthesis

\section{Discussion}

A shorter clinical crown may be a reason for poor retention form thereby leading to improper tooth preparation. Surgical crown lengthening helps to increase the clinical crown length without affecting the biologic width. ${ }^{1}$ Crown-lengthening surgery involves various techniques, including gingivectomy or gingivoplasty or apically positioned flaps, which may or may not include osseous resection. Periodontal crown lengthening is also used in cases of delayed passive eruption, teeth with fractures, subgingival caries or both. This mode of treatment can establish a biological width and a ferrule distance to aid in proper prosthetic management. $^{2}$

Fixed prosthodontic restorations are widely practiced in dentistry today. A thorough periodontal evaluation is a vital aspect for restorative dentistry before proceeding to fixed prosthodontic treatment. During tooth preparation, the periodontal structures must provide a sufficient space to establish a healthy, long lasting and acceptable esthetic restoration.

Some basic considerations must be kept in prior to tooth preparation. This includes status of the clinical crown; whether sufficient tooth structure is present or not; whether it requires crown lengthening by restoration build up or periodontal surgical means (apical extension).

Ideally for posterior tooth restoration, the recommended dimensions are as follows ${ }^{3}$;

Minimum thickness of crown material on occlusal surface $=2 \mathrm{~mm}$

Minimum abutment height $=4-5 \mathrm{~mm}$

Ferrule $=1-1.5 \mathrm{~mm}$ 
Sulcus depth $=1 \mathrm{~mm}$

Biological width $=2 \mathrm{~mm}$

If the required length and dimensions are not there, the above mentioned dimensions need to be restored for an esthetic and durable restoration. In this setting, crown lengthening can be used as one of the most effective procedures prior to tooth restoration as it does not affect the biological width.

Concepts of Biological Width: In 1961, Gargiulo, Wentz and Orban's cadaveric study recognized biologic width as the healthy gingival tissues that occupy above the alveolar bone. They found that in an average human, the connective tissue attachment occupies $1.07 \mathrm{~mm}$ and junctional epithelium occupies another $0.97 \mathrm{~mm}$ above connective tissue attachment. These two measurements together constitutes the biological width. ${ }^{3}$

(Diagram 1) The distance between the base of the sulcus and the crest of the alveolar bone should be 2.04 $\mathrm{mm}$ (0.97 for junctional epithelium and 1.07 for connective tissue attachment).This is minimal width require to attach the collar of gingiva on tooth surface.

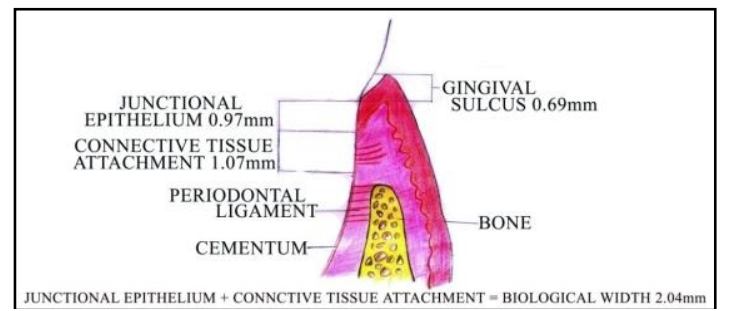

Diagram 1:

Biological width impingement can cause periodontal tissues destruction. Therefore in crown lengthening, the position of the margin should be carefully planned.

Clinical Importance of Biological Width: If the tooth is prepared apical to the base of the sulcus, and margin of a restoration is placed within the biologic width, especially on the connective tissue attachment, the biologic width is affected and the long term gingival health is compromised.

Intracrevicular tooth preparation can lead to low crest dento gingival complex (DGC) or high crest (DGC). While low crest DGC are only prone to recessions, it is the high crest (DGC) that are at risk for biological width violation when the margin is placed more apically below the free gingival margin. Thus, the location of the osseous crest in relation to the gingival margin and future restorative margin is the most critical reference point from both the periodontist and prosthetic dentist's point of view. ${ }^{4}$ Therefore in order to prevent violation of the biological width during intra crevicular tooth preparation the following protocol is recommended. ${ }^{5}$

\section{Main objective of crown lengthening include $;^{6}$}

1. Increase or to preserve or to maintain restorations.

2. Cosmetic improvement.

3. Enables restorative treatment without hampering biological width.

4. Correction of occlusal plane.

5. Removal of subgingival caries.

6. Facilitation of improved oral hygiene.

Indications of Crown Lengthening Include: After careful assessment of periodontal tissue before crown lengthening procedure, the clinical crown is then lengthened apically with an intentional calculated attachment loss. The sufficient amount of residual alveolar bone and a minimum required width of attached gingiva are the pre-requisites before proceeding with the proposed treatment. ${ }^{6,7}$

Diagnostic considerations for crown lengthening include;

1. Significance of the tooth in the dental arch (if it is a key to occlusion or not)

2. Root divergence, root length and root morphology.

3. During the procedure, amount of periodontal support lost from the adjacent tooth.

4. The presence of clinical crown fracture or subgingival caries on the cervical aspect of tooth.

5. Following a restorative treatment, if the clinical crown/root ratio is found to be favorable.

6. The possibility of exposure of furcation as well as unfavorable root surface exposure (including grooves) which may complicate the maintenance.

7. Possibility of increased tooth mobility due to influence of occlusion.

8. Possible esthetic and speech defects.

9. Whether proper plaque control can be maintained after placement of restoration.

After considering the above criteria a judicious decision should be made regarding whether the tooth is fit or suitable for crown lengthening or not.

\section{Preoperative Evaluation in Crown Lengthening Procedure: \\ Determination of Occlusal Plane: Occlusal diagnosis should be made and a desired occlusal plane is determined prior to provisional restorations can be fabricated. This approach enables practitioners to determine how much additional clinical crown length is necessary. ${ }^{8}$}

Esthetic Evaluation: This is mainly focused in relation to the esthetic zone in the maxillary anterior region. In this zone, it is extremely important to identify the position of midline, and the amount of teeth and the soft tissues from the frontal view and lateral view, with both the lip line at rest and when smiling. Uneven gingival architecture, the teeth position relative to the arch shape and opposing occlusion will all affect and dictate the decision-making process. The position of the incisal edge relative to the facial proportions and lip dynamics 
is also considered as critical. A range of $2-3 \mathrm{~mm}$ of marginal gingival visibility is considered as normal during smiling. ${ }^{9}$

Importance of Gingival Biotype: In crown lengthening procedure by osseous resection, the existing gingival morphology (scalloped or flat) must be considered as a thick biotype gingiva return to its original shape and a thin gingiva will react to surgery by a recession.

\section{Procedure of Crown Lengthening:}

Following parameters should be assessed first

1. Anatomic crown relationship of CEJ and bone crest

2. Measuring the zone of attached gingiva

3. Determinants of periodontal biotype

4. The presence of pocket

The first step in crown lengthening is to the anatomical relationships of the bone with respect to the gingival margin. This can be done by transgingival probing which is done by inserting the probe through the anesthetized gingival sulcus towards the crest of alveolar. Transgingival probing also helps to assess the relationship of the gingival crest to the CEJ. This assessment will indicate whether there is gingival excess or normal gingival width. After assessment, any form of surgical treatment for correction will be carried out only if there is a discrepancy in these four criteria namely,

1. Pocket depth.

2. Attached gingival.

3. Level of alveolar bone with respect to the gingival margin.

4. Additional crown length required. ${ }^{10}$

Decision making during Surgery: ${ }^{6}$

1. If the pocket depth is more than $4 \mathrm{~mm}$ with sufficient amount of attached gingiva- simple gingivectomy is indicated (Diagram 2)

2. If pocket more than $4 \mathrm{~mm}$ is present but minimal attached gingiva - apically positioned flap.

3. If no pockets on a short clinical crown with sufficient attached gingiva- flap surgery and osteoplasty (Diagram 3).

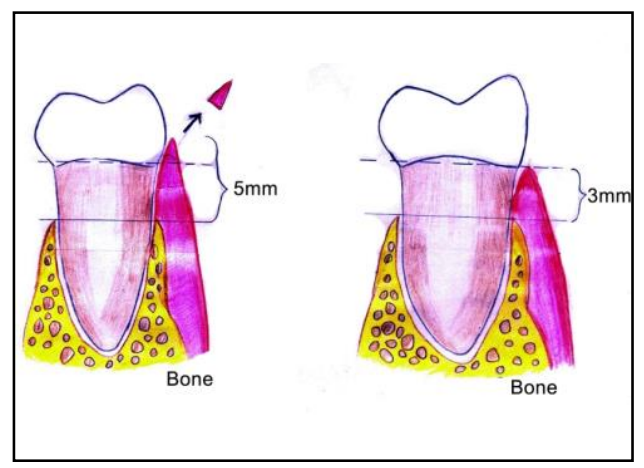

Diagram 2:

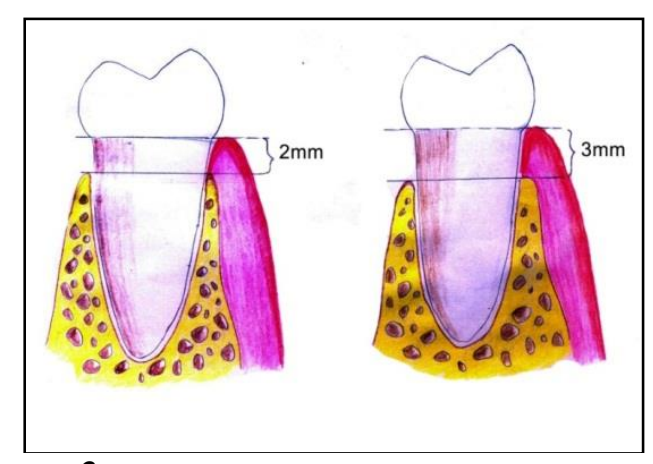

\section{Diagram 3:}

\section{When and how to restore the tooth after surgery}

A restorative treatment should be initiated only after 4-6 months. This is because the margin of the provisional restoration/final restoration may hinder or compromise the healing before the biological width is established by surgical procedures. In case of a thick biotype, the marginal periodontal tissues have a tendency to grow in a coronal direction. Hence in this condition, the definitive crown preparation should be made only after 3 months of surgery. While in a thin periodontal biotype, crown preparation should be done only by 6 months. ${ }^{11}$ Following surgery, the biological width will restore to its original vertical dimension by 6 months. ${ }^{5}$ After surgery, it is even more important for the prosthodontist to use the osseous crest as a reference point during crown preparation and to always follow the scalloping of the free gingival margin. ${ }^{12}$

Therefore, the initiation of final prosthetic treatment should wait for a period of three to six months to allow establishment of the final vertical position of the free gingival margin. ${ }^{2}$

Margin Placement Protocols: The patients existing sulcular depth is used to assess the biological width requirement. This allows placement of the restorative margins relative to the periodontal attachment. While doing so, the bottom of the sulcus is considered as the roof of the attachment, therby allowing the clinician to check for variations in the attachment height as the margin is placed in the sulcus and not in the attachment. However, prior to assessment of sulcus depth, gingival health should be assessed. After making the tissue healthy, the following three rules can be used to place intracrevicular margins:

Rule 1: If the probing sulcus depth is $1.5 \mathrm{~mm}$ or less, the restoration margin $0.5 \mathrm{~mm}$ is placed below the gingival tissue crest. This will prevent biological width violation especially on the labial aspect.

Rule 2: If the probing sulcus depth is more than 1.5 $\mathrm{mm}$, the margin is placed half the depth of the sulcus below the tissue crest. This places the margin far enough below tissue, so that it will still be covered if the patient is at higher risk of recession.

Rule 3: If the probing sulcus depth is greater than 2 $\mathrm{mm}$ is found, especially on the facial aspect of the tooth, a gingivectomy can be performed to lengthen the 
teeth and create a $1.5-\mathrm{mm}$ sulcus. Then the patient can be treated using Rule 1.

Rule 3 is carried out as a deep margin placement is more difficult and the stability of the free gingival margin is less predictable when a deep sulcus exists. ${ }^{13}$

\section{Conclusion}

A proper diagnosis is very essential to determine a meaningful treatment plan. The periodontal restorative team is uniquely positioned to provide the esthetic as well as functional demand of the patient. Equipped with periodontal plastic procedures and technically advanced restorative/prosthetic materials, the periodontal restorative team can provide the patient needs in a better way. The challenge becomes making the correct diagnosis and selecting the appropriate treatment regimen. A comprehensive clinical evaluation and understanding of the etiology will helps to elicit a correct diagnosis. A knowledge about the under lying pathologic process and clinical experience with a proper scientific background leads to a meaningful treatment plan. With an interdisciplinary treatment approach, long term success with high prognostic value can be achieved.

\section{References}

1. Nethravathy R, Vinoth SK, Thomas AV. Three different surgical techniques of crown lengthening: A comparative study. Journal of pharmacy \& bioallied sciences. 2013, 6;5 (Suppl 1):S14.

2. Hempton TJ, Dominici JT. Contemporary crownlengthening therapy: a review. The Journal of the American Dental Association. 2010, 30;141(6):647-55.

3. Newman, Takei, Klokkevold, Carranza-Carranza's Clinical periodontology $10^{\text {th }}$ edition, Saunders-Elsevier Publication 2006, 1044-1066.

4. KOIS JC. Altering gingival levels: the restorative connection part I: biologic variables. Journal of Esthetic and Restorative Dentistry. 1994, 1;6(1):3-7.

5. Lanning SK, Waldrop TC, Gunsolley JC, Maynard JG. Surgical crown lengthening: evaluation of the biological width. Journal of periodontology. 2003, 74(4):8-10.

6. Navshi Sato, Periodontal surgery, a clinical atlas. Quintesence publishing Co. Inc 2000, 33-37.

7. Gerald. J. Chiche, Alain Pinault: Text book on esthetics of anterior FPD, Quintesence publishing Co Inc, 1994, 34-36.

8. Kao RT, Dault S, Frangadakis K, Salehieh JJ. Esthetic crown lengthening: appropriate diagnosis for achieving gingival balance. Journal of the California Dental Association. 2008, 36(3):187-91.

9. Ravon NA, Handelsman M, Levine D. Multidisciplinary care: periodontal aspects to treatment planning the anterior esthetic zone. Journal of the California Dental Association. 2008, 36(8):16-18.

10. Chu SJ, Karabin S, Mistry S. Short tooth syndrome: diagnosis, etiology, and treatment management. CDA J. 2004, 32(2):32.

11. Pontoriero R, Carnevale G. Surgical crown lengthening: a 12-month clinical wound healing study. Journal of Periodontology. 2001, 1;72(7):12-15.
12. Wise MD. Stability of gingival crest after surgery and before anterior crown placement. The Journal of prosthetic dentistry. 1985, 1;53(1):17-19.

13. Newman, Takei, Klokkevold, Carranza-Carranza's Clinical periodontology $11^{\text {th }}$ edition, Saunders-Elsevier Publication 2012, 992-993. 